\title{
O PERIFÉRICO NU: AS FOTOGRAFIAS HOMOERÓTICAS MASCULINAS DE ALAIR GOMES E ROTIMI FANI-KAYODE
}

\author{
THE PERIPHERAL NUDE: THE MALE HOMOEROTIC \\ PHOTOGRAPHS OF ALAIR GOMES AND ROTIMI FANI-KAYODE
}

\begin{abstract}
RESUMO
O objetivo é examinar as semelhanças e as diferenças entre as obras de Alair Gomes e Rotimi Fani-Kayode. O argumento central aponta que ambos procuraram explorar o potencial subversivo do homoerotismo ao trazerem à tona a existência de espaços e tempos dissidentes que desestabilizam normas repulsivas à sociabilidade homoerótica. Gomes revela espaços subversivos em que o desejo pelo corpo masculino seminu e nu e o prazer do voyeur poderiam ser instigados, desenvolvendo narrativas que captavam a espontaneidade e a sensualidade do momento. Já FaniKayode ressaltava o deslocamento espacial e cultural e as múltiplas temporalidades que conviviam no mesmo ambiente, questionando hierarquias a partir da fantasia espiritual e homoerótica e da exaltação da diferença cultural e sexual.
\end{abstract}

Palavras-chave: Fotografia. Homoerotismo. Alair Gomes. Rotimi Fani-Kayode.

\begin{abstract}
The aim is to examine the similarities and differences between the works of Alair Gomes and Rotimi Fani-Kayode. The central argument points out that both sought to exploit the subversive potential of homoeroticism by bringing to light the existence of dissident spaces and times that destabilize repulsive norms to homoerotic sociability. Gomes revealed subversive spaces in which the desire for the naked male body and the pleasure of the voyeur could be instigated and developed narratives that captured the spontaneity and sensuality of the moment. Fani-Kayode emphasized the spatial and cultural deplacement and the multiple temporalities that coexisted in the same environment. He questioned hierarchies based on the spiritual and homoerotic fantasy and the exaltation of cultural and sexual difference.
\end{abstract}

Keywords: Photography. Homoeroticism. Alair Gomes. Rotimi Fani-Kayode.

Diego Santos Vieira de Jesus

ESPM/RJ. Email: dvieira@espm.br 


\section{Introdução}

A fotografia coloca-se como uma expressão imagética que viabiliza a construção de reflexões sobre biografias, sejam de discursos sobre a vida do próprio fotógrafo ou de narrativas das passagens das vidas de outras pessoas. Nos dois casos, o discurso narrativo pelas imagens apreende trajetórias peculiares de vida, combinando os elementos documental e artístico, e promove um espaço para a manifestação do eu artístico em sua singularidade na relação com o ambiente que o cerca (SANTOS, 2008). Ao permitir essa manifestação de múltiplas identidades, a fotografia abriu a possibilidade de se revelarem espaços dissidentes, nos quais se articulam identidades e relações alternativas aos padrões hegemônicos e dominantes em tecidos sociais. Essas "cartografias dissidentes" apresentadas pela fotografia expõem, por exemplo, entendimentos múltiplos das formas como essas identidades podem ser constituídas e as relações interpessoais podem ser construídas fora de parâmetros dominantes relacionados à raça, etnia, gênero e sexualidade em cada sociedade (PEREIRA, 2018; PRECIADO, 2008).

A arte homoerótica - em particular a fotografia homoerótica ${ }^{1}$ - apontava que o mundo não poderia ser compreendido estritamente a partir de noções fixas que circundam o universo masculino, heterossexual, branco e europeu (SANTOS, 2002). Este trabalho propõe-se a explorar como essas expressões subalternas e dissidentes se apresentam nas fotografias homoeróticas masculinas de dois artistas de países da periferia mundial, cuja produção desenvolveu-se em momentos próximos: Alair Gomes e Rotimi Fani-Kayode. Gomes (1921-1992), nascido em Valença, no Rio de Janeiro, mudou-se ainda criança para a capital do estado, onde veio a atuar como artista durante as décadas de 1970 e 1980. Autodidata na fotografia, Gomes - um engenheiro de formação - foi contratado por Burle Marx no fim da década de 1960 para o registro de espécies botânicas de seu sítio. Logo após, começou a se dedicar a fotografar rapazes nas ruas do bairro de Ipanema, onde morava, e produzir longas sequências, que o tornaram um precursor do homoerotismo masculino da fotografia no Brasil (SANTOS, 2008). Fani-Kayode (1955-1989) nasceu em Lagos, na Nigéria, numa família de tradição iorubá e se mudou para a Inglaterra aos 12 anos, fugindo da Guerra Civil em seu país de origem. A maior parte de sua obra, produzida entre 1982 e 1989, explorou as tensões entre sexualidade, raça e tradições culturais por meio de fotografias de corpos de homens negros nus e seminus, inclusive o do próprio artista. O corpo masculino negro era o ponto central de sua produção, a partir do qual ele explorava a relação entre a fantasia homoerótica e os valores espirituais ancestrais, em uma experiência complexa que envolvia a sexualidade e os sentidos de deslocamento, rejeição e separação. Tal produção também carregava críticas ao racismo e ao colonialismo, bem como as tensões entre a homossexualidade do artista e os valores tradicionais de sua formação iorubá (MERCER, 1999).

1 Entende-se neste artigo que "fotografia homoerótica" refere-se à fotografia produzida com viés homoerótico tanto por conta do olhar do fotógrafo como pelo conteúdo apresentado na fotografia. 
O objetivo deste artigo é examinar as semelhanças e as diferenças entre as obras de Alair Gomes e Rotimi Fani-Kayode, inseridos no contexto da produção fotográfica homoerótica masculina da periferia, fora do mainstream norte-atlântico. $\mathrm{O}$ argumento central aponta que ambos os artistas procuraram explorar o potencial subversivo do homoerotismo ao trazerem à tona a existência de espaços e tempos dissidentes que desestabilizam normas repulsivas à sociabilidade homoerótica. $\mathrm{O}$ corpo nu e seminu masculino em contextos homoeróticos desestabiliza os códigos e convenções tradicionalmente associados à masculinidade hegemônica. Gomes revela espaços subversivos ao machismo, ao patriarcado e à homofobia vigentes na sociedade brasileira, em que o desejo pelo corpo masculino seminu e nu e o prazer do voyeur poderiam ser instigados, desenvolvendo narrativas que captavam a instantaneidade, a espontaneidade e a sensualidade do momento. Já Fani-Kayode ressaltava o deslocamento espacial e cultural dos "outsiders" - no caso, do homem homossexual negro da Diáspora Africana - e as múltiplas temporalidades que conviviam no mesmo ambiente, como as tradições das sociedades africanas e as opressões do presente. A fotografia homoerótica operava como um meio de questionamento de hierarquias impostas por uma sociedade patriarcal e racista a partir da exploração da fantasia espiritual e erótica e, ao mesmo tempo, da exaltação da diferença cultural e sexual.

A seguir, examinarei os principais elementos que caracterizam a fotografia homoerótica masculina da periferia. Em seguida, analisarei os principais aspectos do homoerotismo masculino nas obras de Gomes e Fani-Kayode, respectivamente. Antes de tecer as considerações finais, explorarei a comparação entre as obras de ambos os artistas.

\section{A fotografia homoerótica masculina da periferia}

As tentativas de construção da masculinidade heterossexual em oposição à homossexual passaram por ações de higienização da vida social, que mobilizavam a violência simbólica para efetuar a disciplina sobre os corpos dos indivíduos. A medicalização da homossexualidade acompanhou o refinamento de outras técnicas de vigilância sexual, que qualificavam o casamento como divino e a fidelidade como condição para a sobrevivência da família e colocavam que as formas desviantes de sexualidade deveriam ser investigadas e normatizadas (MENDONÇA, 2012). Instituições médicas e psicológicas, governos e igrejas faziam circular discursos de classificação em torno do corpo e da identidade homossexuais, de forma a atuarem no enquadramento de tais subjetividades desviantes (FEATHERSTONE, 1995). Se por um lado os termos jurídicos e as ciências médicas e psicológicas instrumentalizavam a violência simbólica em relação a homossexuais e o saber produzido sobre seu corpo operava como um controlador social, as ações de resistência por meio da literatura, das artes visuais e de parte da mídia estabeleciam as fronteiras de um território existencial comum, nos quais se produziam experiências coletivas de múltiplas 
formas de identidade sexual. Esses espaços escapavam à dominação verticalizada do poder e geravam redes simbólicas capazes de significar as identidades homossexuais (VILLAAMIL, 2004).

Sendo dotado de historicidade, o regime de visibilidade do corpo masculino gradualmente se realiza por meio de fluxos comunicacionais que engendram diferentes processos de subjetivação (HOFF, 2016). As primeiras fotografias de corpos nus ou seminus masculinos tinham propósitos científicos, como, por exemplo, demonstrar o funcionamento da locomoção. Porém, no final do século XIX, uma série de fotógrafos - em especial o Barão von Gloeden e Guglielmo Plüschow - registrava corpos de homens nus de forma artística, muitas vezes em interação com a natureza. Com o surgimento de catálogos de nu masculino e a presença gradualmente erotizada de homens másculos no cinema - tendo atores como Tab Hunter, James Dean e Marlon Brando como exemplos -, o padrão estético de um corpo másculo e vigoroso disseminou-se ao redor do mundo, de forma a estimular o culto ao corpo masculino em academias de ginástica e publicações destinadas a esse mercado. Os textos visuais e verbais dessas revistas muitas vezes lembravam a imagem do homem retratado em pinturas renascentistas, representado em toda a sua potência na valorização de partes de seu corpo e na mobilização de símbolos fálicos que acompanhavam a imagem. A qualidade estética da obra de fotógrafos como Pierre et Gilles e Robert Mapplethorpe fez com que as fotografias de homens nus ou seminus deixassem de ser consideradas por críticos apenas elementos de interesse restrito aos desejos femininos e gays, mas como objetos artísticos (MENDONÇA, 2012; TAMAGNE, 2013).

Nesse contexto, a relação entre o homoerotismo e a fotografia mostravase cada vez mais interligada à dinâmica discursiva de artistas e populações LGBT, sinalizando algumas de suas proposições artísticas contemporâneas, como a ação afirmativa de cenas homoeróticas entre homens. A partir de recursos técnicos e estilísticos, o sujeito era posicionado na fotografia de maneira afirmativa, e o produto contextual, cujo foco estava nas narratividades identitárias e culturais, apresentavase na vivência ou na prática em que arte e sexualidade se intercambiavam. Os elementos constitutivos da fotografia homoerótica buscavam afinar-se com o público, de forma que tal produto cultural e o seu apreciador alimentavam uma realização poética. Esse produto tipicamente podia ser tomado como uma manifestação do seu agente criador e realizador, em particular seu processo criativo e suas experiências afetiva e erótica. Com base em suas experiências particulares e sociais, os artistas que realizavam fotografias homoeróticas masculinas formavam múltiplos campos de experimentações sensíveis e diferenciadoras, que incorporavam suas transformações pessoais (GARCIA, 2012).

A fotografia homoerótica masculina realizada por artistas de origens latinoamericana, africana e asiática - aqui denominada "fotografia homoerótica masculina da periferia" - buscava, como suas contrapartes norte-atlânticas e eurocêntricas, desafiar sistemas hegemônicos que designavam poderes institucionais para conter e disciplinar o discurso homoerótico. O homoerotismo e a imagem nessa fotografia casavam-se na problematização de paradigmas identitários, socioculturais e 
políticos, de forma que as reconfigurações trazidas por tais artistas evidenciavamse em suas expressões artísticas e estéticas, em uma ênfase homoerótica. A organização instrumental dessas fotografias apontava para uma orientação reflexiva que contextualizava diferentes modos de observação e leitura e ampliava o leque de possibilidades enunciativas sobre a dinâmica de alteridades homoeróticas, que carregavam com elas ambiguidade, resistência e ironia (GARCIA, 2012).

Entretanto, a particularidade da fotografia homoerótica masculina da periferia estava em desvelar que era necessário atentar para especificidade cultural de outras regiões fora da região norte-atlântica. Em tais regiões, articulavam-se regimes locais específicos de exclusão, que reproduziam padrões homofóbicos (MISKOLCI, 2013) e tornavam invisíveis aqueles que não se enquadravam nos estereótipos heteronormativos e homonormativos culturalmente definidos da masculinidade hegemônica, um conjunto de práticas culturalmente espaço-temporais específicas que legitimava ideologicamente a subordinação feminina (CONNELL, 1993; CONNELL; MESSERSCHMIDT, 2005), diferenciava-se hierarquicamente de outras masculinidades - como as homossexuais - e se sustentava socialmente pela heterossexualidade e pela homofobia (DONALDSON, 1993). Nesse sentido, a fotografia homoerótica masculina da periferia não apenas levava em conta a relação do corpo masculino nu ou seminu com as potencialidades do local específico em que tal corpo estava imerso - revelando espaços subversivos para o fomento e a realização do desejo homoerótico -, mas o resgate crítico dos elementos da cultura na qual o corpo desse homem tinha sido significado para se desvelarem suas potencialidades estéticas e políticas de desestabilização de padrões socioculturais hierarquizantes que tentavam discipliná-lo.

$\mathrm{Na}$ linha apresentada por Halberstam (2005), argumenta-se que a fotografia homoerótica masculina da periferia permite pensar espacialidades e temporalidades que escapam a padrões dominantes no que diz respeito ao gênero e às sexualidades. Quanto às espacialidades, tal fotografia apreende lógicas de localização, movimento e identificação que fogem aos espaços disciplinados e domesticados com relação à heterossexualidade e à reprodução, como o espaço da família. Nessas lógicas subalternas, o espaço é apropriado por sujeitos que subvertem as normativas de gênero e sexualidade, criando entendimentos alternativos sobre eles mesmos, as relações entre eles e o próprio espaço. Em relação às temporalidades, os sistemas temporais burgueses alinhados à reprodução e à família e a organização eurocêntrica linear e progressiva do tempo - que coloca elementos culturais de sociedades periféricas como sinônimos de "atraso", "barbárie" ou "primitivismo" - podem ser pervertidos em tais fotografias ao se captar a efemeridade do instante marcado pela espontaneidade e pelo risco das relações ocasionais que fogem a padrões dominantes, bem como a permanência de elementos culturais que valorizam a particularidade de sociedades periféricas em meio a discursos de progresso e desenvolvimento, baseados em noções eurocêntricas de sistematização de sociedades em escalas temporais lineares. 


\section{O periférico nu e seminu na obra de Alair Gomes}

O olhar artístico, voyeur e homoerótico de Gomes - que se insere no universo da chamada "fotografia de autor" - situava o corpo nu e seminu masculino como objeto de desejo e conquista, captado pela câmera (CHIARELLI, 1999). Se por um lado a poética íntima e pessoal do fotógrafo era marcada por uma estética ousada e criativa, ela também se recobria com sensualidade afetiva e erótica, que alimentava anseios internos que iam além da pornografia. O fascínio pela beleza masculina conduzia a uma forma criteriosa e precisa de fotografar: Gomes passava os dias na janela de seu apartamento, em frente à praia de Ipanema, com uma câmera fotográfica com lente teleobjetiva, e aguardava o melhor ângulo dos banhistas, com corpos suados e contornos musculares trabalhados. O registro à distância dos corpos seminus dos rapazes na praia capturava as imagens desses corpos de forma inusitada e natural, como se estivessem expostos sem objeção, e permitiam uma vivência ampliada do observador, tanto do próprio Gomes no momento da captação, como do público diante das fotografias apresentadas nas exposições. O ideal erótico na imagem da nudez ou da seminudez masculina permitia criar atrativos na imaginação do observador, trazendo visões sobre o corpo masculino que desestabilizavam aspectos socioculturais permeados pelo preconceito e pela discriminação e a peculiaridade do cotidiano erótico do lugar (GARCIA, 2012).

Argumenta-se, a partir de tal reflexão inicial sobre a obra de Gomes, que a sua "fotografia de autor" - marcada pelo voyeurismo de forte cunho homoerótico revelava espaços subversivos em que o desejo pelo corpo masculino seminu podia ser instigado e alimentado. Ainda que grande parte dos corpos retratados fosse de jovens das classes média e alta das áreas nobres da Zona Sul do Rio de Janeiro - o que, de certa forma, esvaziava das fotos o tratamento de questões relacionadas à disparidade entre classes sociais -, a visualidade poética de seus corpos e sua relação com o ambiente nas fotografias de Gomes relacionavam-se à particularidade da "cultura da praia" associada ao Rio de Janeiro e à existência de zonas de contato sociocultural com corpos masculinos que fugiam a regimes de controle da sexualidade vigentes na sociedade brasileira, marcados por machismo, patriarcalismo e homofobia. Essas "zonas de contato" - constituídas em muitas fotos de Gomes a partir de situações cotidianas - revelavam a dinâmica de aproximação entre o fotógrafo e o modelo, cujo corpo era captado e desejado pelo artista.

De acordo com Ellenzweig (1992), Gomes explorava a plasticidade do corpo masculino pela fascinação com que perseguia tais corpos na praia, de forma a expressar o desejo homoerótico numa posição que se distancia da atitude pornográfica - que escandalizava a vulgaridade e evidenciava a obscenidade - e se aproximava da contemplação da imagem do corpo, ressaltando a beleza e a sensibilidade das suas formas a partir de um olhar voyeur (ELLENZWEIG, 1992). Cabe, assim, realizar o contraponto da proposta de Gomes com a de fotógrafos de corpos nus e seminus masculinos do eixo norte-atlântico, como Mapplethorpe. Embora ambos os artistas 
almejassem incluir em suas obras o desejo de experiência da transcendência do sexo, Mapplethorpe explorava o vigor sexual e a teatralidade de corpos identificados que se aproximavam da perfeição da escultura clássica, cuidadosamente posados, iluminados e retratados em recortes precisos que destacavam suas qualidades escultóricas, como volume, peso e superfície. Nas fotos em que retratava o nu masculino frequentemente no interior de seu apartamento, para onde convidava os rapazes que via na praia a posarem para ele -, Gomes explorava um "corpo natural" anônimo, que era belo, mas não extremamente hipertrofiado como os corpos frequentemente expostos na obra do fotógrafo norte-americano. Ainda que tivesse uma preocupação com uma representação clássica de um corpo-escultura, Gomes captava os corpos em natureza espontânea, de forma que grande parte das fotografias não eram tão posadas, iluminadas ou precisas como as de Mapplehorpe (SOUZA, 2017).

Mapplethorpe também identificava a praia como um local hedônico, mas, enquanto ele optava por apresentar corpos que se integravam a relevos e os imitavam, Gomes concedia às imagens um alcance maior, que, por conta do uso da lente teleobjetiva em obras como "Sonatinas, Four Feet (1970-1980)", eram menos nítidas, de forma a ressaltar a composição geométrica dos corpos e, ao mesmo tempo, a explicitação da interação e da intimidade entre os homens retratados a partir de códigos alternativos aos da masculinidade hegemônica vigente na sociedade brasileira no período em foco (SOUZA, 2017). Despertava-se o sentido do inatingível, evocado pela fotografia que estimulava sentimentos eróticos nas pessoas para quem a desejabilidade era intensificada pela distância (SONTAG, 2004). A pulsão que orientava essas imagens revelava a imersão de Gomes no entorno socioespacial de Ipanema, de forma a erotizá-lo ao fotografar os corpos na praia desse bairro recompondo as imagens e imprimindo a eles significados inauditos. A relação erótica dos corpos masculinos situados numa trama social com seu espaço e tempo particulares era mediada pela corporeidade. Tanto o bairro como os homens que nele eram retratados como entes belos, aprazíveis e desejáveis revelavam a conexão entre o imaginário homoerótico de Gomes - por meio de fotografias que traduziam seu mundo interior - e o imaginário socioespacial de Ipanema, um mundo exterior para o qual se direcionavam as emoções, os sentimentos e as pulsões homoeróticas do artista (LIMA, 2017).

As apropriações fotográficas em "Sonatinas" não se caracterizavam apenas como coletas de um documento, mas a realização metafórica dos desejos do artista a partir da promoção de um ato criador com corpos alheios. A escrita pessoal das imagens - aparentemente despretensiosa - era transgressora na medida em que a edição das sequências simulava, pelos ângulos das fotografias e pela montagem, a sutileza de cenas homoeróticas que sugeriam o flerte, as carícias e, por vezes, até mesmo o ato sexual (SANTOS, 2008). Ao mesmo tempo, tais fotografias preservavam o prazer do voyeur de não se envolver diretamente com o objeto de seu vislumbre e de sua busca, alimentando a imaginação homoerótica acerca do corpo retratado. Nas fotos em que o corpo masculino aparecia nu em uma praia - como em "Nu - Praia" -, o artista captava a agilidade e a leveza do instante em que o rapaz retratado entrava 
nu no mar, numa narrativa que capturava o movimento e a sensualidade em ação (BARATA, 2014).

Nesse sentido, Gomes trazia uma cartografia não apenas do afrouxamento de códigos baseados em modelos dominantes de estruturação da sexualidade, mas da forma como as relações entre homens deveriam ocorrer no espaço público. As imagens captadas na praia em plena luz do dia escapavam ao repertório imaginativo de espaços nos quais esses encontros ocorriam (PEREIRA, 2018). As práticas homoeróticas em geral são associadas a territórios marginais onde se pratica sexo anônimo e impessoal (PERLONGHER, 2005). O espaço público na modernidade ocidental é usualmente concebido como um ambiente repressor a dissidências das normativas de gênero e sexualidade (PRECIADO, 2008). Entretanto, a fotografia de Gomes captava contextos - ainda que não exclusivos - de sociabilidade entre homens, apresentando o desejo e o erotismo que os permeavam, mesmo quando não havia a expectativa de que esses elementos compusessem o repertório desses encontros. Gomes retratava um contexto de homossocialidade e de homoerotismo nas praias cariocas, fora dos locais onde tipicamente relações afetivas, eróticas ou sexuais entre homens seriam imaginadas, como saunas ou bares gays. $\mathrm{O}$ espaço improvável do que parecia imperceptível aos padrões de uma sociedade machista e homofóbica tornava-se, assim, visível na produção do artista (PEREIRA, 2018). A visão pornotrópica do Rio de Janeiro, marcada pela exuberância da paisagem e por mulheres sensuais (MCCLINTOCK, 1995), tornava-se um "inventário da exuberância corporal masculina” (SANTOS, 2009, p.31), carregado de homoerotismo, num enfrentamento simbólico direto com visões dominantes heteronormativas sobre a cidade e seus habitantes (LIMA, 2017).

\section{O periférico nu e seminu na obra de Rotimi Fani-Kayode}

Fani-Kayode definiu um universo fotográfico no qual o corpo masculino nu e seminu de homens negros operava como o ponto de partida para a exploração da relação entre a fantasia erótica e os valores espirituais ancestrais. Sem jamais se confinar ao conforto e à segurança de uma única identidade, a visão caleidoscópica do artista - que combinava elementos africanos e europeus na sua produção - e a demanda do prazer carnal traziam um encontro intenso com a realidade emocional dos corpos retratados, que carregavam com eles experiências características da Diáspora, como a migração, o deslocamento, o trauma da separação e o regresso imaginado. Tais experiências apareciam ligadas a acontecimentos da vida do próprio Fani-Kayode, de forma a revelar que a sexualidade assumia papel fundamental na descoberta de suas raízes artísticas e no domínio do sagrado com a afirmação do amor pela vida e o poder redentor de Eros. Ao impor a ruptura entre o artista e suas origens, a diáspora trazia uma lacuna que funcionava como catalisador de sua criatividade a partir do seu compromisso com a paixão homossexual e o homoerotismo. O paradoxo 
que se colocava na possibilidade de encontro da liberdade pela perda das origens e a recuperação delas pela viagem à memória ancestral do corpo situavam Fani-Kayode num espaço e num tempo que resultavam de conflitos essenciais, fundamentais à luta por novas visões sobre os corpos e as sociedades. A condição subalterna de FaniKayode permitia, em sua obra, valorizar novas práticas de liberdade ao tratar, de forma subversiva, o fetichismo racial que predominava na visão ocidental acerca do corpo negro. Como sua relação com as origens iorubas era mediada pelas rupturas da Diáspora, o corpo negro masculino integrava, na produção de Fani-Kayode, a inseparabilidade do hibridismo e da homossexualidade, revelando-se uma atitude crítica em relação às noções de identidades estáveis, íntegras e coesas, que dominavam a cultura ocidental (MERCER, 1999).

As fotografias de Fani-Kayode exploravam - e celebravam - a sexualidade, a etnicidade e o hibridismo, elementos que constituíram o núcleo de sua produção. Ainda que se dissesse inspirado pela obra de Mapplethorpe, a produção de FaniKayode jamais foi derivada da obra do artista norte-americano; ao contrário, seu trabalho foi significativamente influenciado pelos seus esforços pessoais diante do conflito entre sua homossexualidade e sua formação tradicional iorubá. Enquanto um fotógrafo homossexual nigeriano, seu trabalho não era respeitado em sua terra natal por conta de valores tradicionais da sociedade e dos impedimentos familiares quanto à prática da fotografia, ao passo que, no Ocidente, permanecia ignorado diante das obras de artistas europeus e norte-americanos. Entretanto, sua fotografia era mais do que meramente um mecanismo para a promoção de choques de valores ou uma forma elaborada de autoexpressão, ainda que também cumprisse essas funções. Elas retratavam a riqueza e a diversidade de sua origem, numa espécie de narrativa visual de suas experiências pessoais enquanto um homem negro, homossexual e africano (AHMED, 2016).

Em vez de reforçar dicotomias bem definidas entre sujeito e objeto - muito claras na obra de Mapplethorpe, na qual a fetichização do corpo negro visava a repelir a ameaça da perda de controle do Ego -, Fani-Kayode interpelava o olhar do observador com o ritual de máscaras típicas de sua cultura africana, articulando linhas de visão que convergiam sobre o corpo do homem negro nu e traziam a sensação de oscilação entre o mundo erótico e o sagrado (ENWEZOR, 2003; MERCER, 1999). Os corpos masculinos nus dançavam e se entrelaçavam em uma espécie de êxtase erótico, que relembravam os rituais alucinatórios na cultura iorubá. Na proposta das fotografias do artista, o opressor e o oprimido, o sujeito e o objeto se combinavam no mesmo espaço físico e psíquico, de forma que tal síntese questionava os binarismos sociais de identidade e representava os corpos interseccionais e diaspóricos, que resistiam às classificações convencionais. A fotografia de Fani-Kayode dava voz àqueles que não a tinham e celebrava os que tinham sido afastados da visão pública, numa tentativa ainda mais ampla de situar a arte como um espaço em que espacialidades e temporalidades alternativos poderiam existir. Como um "outsider" sexual, o artista via no desejo a fonte mais poderosa de energia inconsciente, na qual o espírito penetrava o corpo. Num ritual de possessão religiosa, o êxtase penetrante marca a 
transição entre o mundano e o espiritual, numa sensação física de transcendência. O processo de êxtase sugerido pela obra de Fani-Kayode reproduzia essa relação espiritual, permitindo ao fotógrafo transcender um mundo que negava a ele o direito de agir com base em seus desejos homoeróticos (MOFFITT, 2015).

Em obras como "Nothing to Lose XII (Bodies of Experience)", as frutas eram estrategicamente colocadas a fim de sugerir um senso de desejo puro de uma forma que era, ao mesmo tempo, sutil e forte. A colocação cuidadosa de sujeitos expostos contra um fundo preto, com uma luz suave que destacava algumas das características de seus corpos, abria margens múltiplas de interpretação. As expressões de melancolia contribuíam para o ar de vulnerabilidade diante dos conflitos vividos pelo homem homossexual, a ambiguidade em relação a seus sentimentos e a sensualidade homoerótica. Como os corpos negros nus teriam "nada a perder" como sugere o título da obra -, eles optavam por transgredir os constrangimentos de uma masculinidade hegemônica em busca de liberdades ainda maiores (MOFFITT, 2015). Ao mesmo tempo, em outras obras, Fani-Kayode mantinha um esforço de preservação da natureza bruta da imagem, como em “The Golden Phallus”, de 1989. A obra trazia uma representação abstrata de como a luxúria e o desejo estavam combinados em circunstâncias que fugiam ao controle do artista, colocando uma crítica à vergonha e ao medo de vivência plena da sexualidade. Colocava-se, assim, uma barreira entre o modelo e o público, a qual oferecia o anonimato ao modelo pelo uso de uma máscara branca e preservava o público da experiência de olhar diretamente nos olhos do sujeito retratado (AHMED, 2016). Essa obra carregava consigo uma expressão irônica do menosprezo ocidental pela virilidade negra, evidente na obrigação simbólica de ser e não apenas ter o falo. $\mathrm{O}$ pênis - pintado com a cor dourada - era atado a cordas, como se a parte mais íntima e erótica do corpo masculino fosse manipulada como uma marionete. Aqui, o homem negro, reduzido pela sociedade branca a um falo fetichizado, era privado do direito de usar livremente seu próprio pênis. A obra referia-se em parte às leis que criminalizavam a homossexualidade, que foram derrubadas no Reino Unido - onde Fani-Kayode desenvolveu grande parte da sua carreira -, mas se mantinham em vigor em seu país de origem (MOFFITT, 2015). Em “Technique of Ecstasy”, o rosto, concentrado no desejo, era removido do olhar do observador, de forma a reivindicar a sexualidade do corpo do homem negro sem fazer dela um mero objeto de contemplação. Em tal obra, aparecia novamente a incômoda "máscara", que remetia ao resgate crítico das tradições africanas e revelava a ruptura com as apropriações dessa cultura por artistas europeus, que a fetichizavam (MERCER, 1999). O interesse na ideia ioruba de "técnica de êxtase" apontava para o transe pelo qual o líder religioso - ou o "pai dos segredos" - era possuído antes de se comunicar com as divindades, da mesma forma como Fani-Kayode parecia acreditar que o artista precisava estabelecer uma relação com seu inconsciente (ZAYA, 1996).

Além de explorar criticamente a percepção tradicional da homossexualidade como ilícita, Fani-Kayode também lidou com as questões de pertencimento. Ele frequentemente se colocava como um "outsider" em termos de sexualidade e de 
deslocamento geográfico e cultural. Algumas de suas obras também incorporavam elementos de rituais ancestrais a fim de retratar o sofrimento e a esperança. Em "Nothing to Lose VIII" (1989), ele apresentava um sujeito solene, com adornos tribais e segurando uma faca, o que simbolizava o sacrifício dos "outsiders" que eram forçados a se adaptar a modelos tidos como aceitáveis pela sociedade branca, heterossexual e euroatlântica. Nas fotografias do artista, os conceitos de tempo e espaço eram amplamente relativizados, de forma que o espaço a todo momento evidenciava o deslocamento cultural dos "outsiders" e as múltiplas temporalidades como as tradições das sociedades africanas e as opressões do presente - conviviam na mesma ambiência. O retrato de homens negros nus funcionava como uma forma de questionar as hierarquias impostas pela sociedade patriarcal e racista por meio da fantasia espiritual e erótica e, ao mesmo tempo, da exaltação da diferença cultural e sexual (AHMED, 2016). Tal exaltação remetia a uma leitura crítica da ancestralidade iorubá, que operava como uma fonte profunda de significação espiritual e artística para o artista, mas também como uma cultura que rejeitava sua orientação sexual e impunha a ele um exílio geográfico e psicológico (MOFFITT, 2015).

A dimensão da transformação cultural ocorrida em situações de deslocamento e realocação era um território complexo que desestabilizava suposições eurocêntricas sobre a representação do corpo masculino negro, advertindo que um único significado ou ponto de referência poderiam ativar rotinas sistemáticas de projeção, identificação e apropriação. A reapropriação da cosmologia iorubá não visava, na obra de FaniKayode, a uma recuperação artificial da tradição africana, como grande aprte da burguesia homossexual euroatlântica fazia ao explorar a mitologia da virilidade negra e conduzir a uma objetificação do continente africano visando à ampliação dos lucros com obras artísticas. A produção do artista nigeriano conduzia o espectador a uma experiência estética de hidridização delirante. Isso ficava claro na obra "Bronze Head", de 1987, em que o fotógrafo apresentava duas imagens posicionadas de maneira oposta: a de uma cabeça de bronze nigeriana e a das nádegas de um homem negro nu. Enquanto a primeira representava a tradição africana, a segunda evocava o homorotismo. A grande cabeça africana parecia estar penetrando o corpo, enquanto o corpo parecia liberar a cabeça, como se estivessem em um estado de flutuação constante, marcado pela tensão cultural e sexual. Esse local de comunhão e confrontação, de integração e exílio, era também um espaço de negociação entre a tradição e o desejo, um processo de transformação em termos de sexualidade num contexto de deslocamento geográfico e cultural (ZAYA, 1996). 


\section{Os periféricos nus e seminus em perspectiva comparada}

O reconhecimento das poéticas informadas pelos dois fotógrafos mostra-se interligado à emergência de uma arte com conteúdo biográfico mais acentuado, de certa forma ampliado em face de discussões múltiplas referentes à vida privada no plano público, que buscavam reagir a constrangimentos anteriores para que fossem encaradas as micropolíticas dos cotidianos culturalmente específicos relacionadas às sexualidades (SANTOS, 2008). As sexualidades dissidentes inscritas nos espaços retratados pelos artistas cujas obras são analisadas neste estudo retratavam novos "campos de possível", heterotopias que se definiam como lugares da sociedade que não se coadunavam a valores dominantes e subvertiam códigos prescritos previamente pela moral de uma sociedade. Tais heterotopias funcionavam de maneira variável historicamente e se mostravam associadas às heterocronias, que rompiam com o tempo tradicional e podiam, por exemplo, desvelar a existência de múltiplas temporalidades num mesmo espaço (FOUCAULT, 2001).

Ao trazerem à tona espaços e tempos dissidentes, as obras de Gomes e de Fani-Kayode desestabilizavam normas instituídas que faziam do espaço público um ambiente repulsivo à homossexualidade e ao homoerotismo (MISKOLCI, 2009) e as noções de que a sociabilidade homoerótica entre homens articulava-se somente em guetos para o encontro entre parceiros sexuais ou pontos de evasão de desejos sexuais reprimidos (GREEN, 20oo; PERLONGHER, 2008). Nesse sentido, ambos parecem propor uma experiência com o corpo nu e seminu masculino que desestabilizava os códigos e convenções tradicionalmente associados à masculinidade hegemônica (CONNELL, 1995) como signos de virilidade, domínio e violência (PEREIRA, 2018). As obras de ambos os artistas traziam, de formas distintas, o jogo sutil de tendências particularizantes e universalizantes, que subvertiam as hierarquias que vigoravam nas suas sociedades e estavam na base do regime de controle dos corpos e da sexualidade, de forma a revelarem o potencial subversivo do homoerotismo (MERCER, 1999). O corpo tornava-se, assim, um local da política de identidade e de contestação (ZAYA, 1996).

A recorrência ao homoerotismo na produção da arte como estratégia discursiva para a exploração de espaços subversivos onde se pudesse fomentar e realizar o desejo homoerótico mostrava-se presente na obra de Gomes. As imagens produzidas pelo artista ocupavam-se extensivamente do corpo masculino, o qual se configurava como o desejo motriz de sua visão. Em grande parte da produção de Gomes entre 1966 e 1986, sua fotografia - registrada a partir da janela de seu apartamento - dedicava-se a garotos se exercitando na orla da praia de Ipanema e à interação entre eles. Em algumas imagens, o artista fotografava os corpos nus de vários desses rapazes, convidados por Gomes a fazerem tais sessões de fotografias em seu apartamento (COSTA; FERREIRA, 2016). Ainda que o corpo masculino fosse visto por Gomes como um objeto plástico que remetia ao classicismo antigo, tal corpo se reconfigurava como um objeto de desejo assumido pelo artista, excitando 
e lembrando que o ato de olhar tinha, nele mesmo, um elemento de obstinação voyeurística (SANTOS, 2002). Revelavam-se espaços de dissidência em que o desejo homoerótico poderia ser instigado, apesar da vigência de regimes socioculturais específicos de controle da sexualidade - no caso, de um Brasil ainda marcado por valores machistas e homofóbicos.

Na obra de Fani-Kayode, o corpo negro masculino nu - enquadrado ao centro - era ornado por acessórios e máscaras que revelavam o interesse do artista pelo contexto iorubá. Entretanto, o ponto de referência africano era acompanhado por outros sentidos que advinham de códigos privados e pessoais, nos quais a homossexualidade e o homoerotismo afloravam (MERCER, 1999). A representação homoerótica nas artes visuais para aqueles que fizeram parte da Diáspora Africana ficou mais evidente no fim do século XX. Inserido em tal contexto, Fani-Kayode incorporava o desejo na representação dele mesmo e de outras vidas e sexualidades que permaneciam ignoradas ou suprimidas, sendo que o corpo negro masculino era o foco desse desejo. $\mathrm{O}$ ato de fotografar validava o sujeito retratado, de forma que, tanto para o artista como o público, o processo artístico funcionava como uma espécie de terapia em que as chagas eram abertas e curadas por meio do poder de visualização. No caso da obra de Fani-Kayode e tantos artistas da Diáspora, o resgate crítico do imaginário histórico constituía-se como um elemento essencial do empoderamento homossexual e uma forma de rejeição de estereótipos baseados na sua própria reavaliação das identidades que lhes eram impostas. Quanto à obra de Fani-Kayode especificamente, pode-se dizer que o artista - que veio de uma família de religiosos iorubás - explorou sua sexualidade por meio de autorretratos íntimos e fotografias de homens negros, em que o corpo tornava-se um ícone e uma metáfora do deslocamento cultural, da espiritualidade e da sexualidade (ENWEZOR, 2003; WILLIAMS, 2002). A fotografia do artista combatia o ódio ao retratar eroticamente os corpos negros nus interseccionais em seus próprios termos, com diálogos com as estruturas de poder que oprimiam esses corpos, de forma a exaltar o desejo homoerótico a patamares semelhantes ou superiores aos altares transcendentais da religião (MOFFITT, 2015).

\section{Considerações finais}

O caráter transgressor da fotografia homoerótica masculina da periferia oferece uma contrapartida à herança da fotografia tradicional - particularmente em relação às iconografias do retrato e do nu - ao trazer visibilidade à existência de territórios subversivos nos quais o desejo homoerótico poderia ser fomentado (SANTOS, 2002), bem como ao resgate crítico da cultura em que os corpos masculinos foram significados a fim de se trazer à tona o potencial transgressor desses corpos ao desconstruir padrões normalizantes e hierarquizantes que buscaram controlalos e discipliná-los. Apesar dessa semelhança nos propósitos das obras de Gomes e 
Fani-Kayode, ambos trouxeram questionamentos a padrões sociais excludentes de maneiras distintas.

Os registros fotográficos de Gomes, feitos com naturalidade, apreendiam a vivência cotidiana da praia num cenário de apropriações múltiplas; porém, o fotógrafo - enquanto voyeur - gerava enquadramentos e aproximações que potencializavam os corpos retratados por meio do desejo (COSTA; FERREIRA, 2016). Em resposta ao prazer encontrado na observação dos corpos masculinos e de suas interações homoeróticas, o artista desvelava as relações desses corpos com as potencialidades do local específico em que estavam inseridos, revelando espaços subversivos que pervertiam normas machistas e homofóbicas de um país e alimentavam o desejo homoerótico. Já na obra de Fani-Kayode, evidenciava-se a crítica à violência sobre o corpo negro que negava a legitimidade do desejo homoerótico, a fluidez do gênero e a subjetividade dos povos não-europeus. Com isso, o artista contestava a hegemonia de padrões ocidentais ao fundir elementos de sua construção estética de forma ambígua e dialógica, de maneira que as formas tradicionais da cosmologia iorubá permitiam a ele examinar os desafios da interseccionalidade e da identidade diaspórica (MOFFITT, 2015).

\section{Referências}

AHMED, Nashwah. Rotimi Fani-Kayode (1955-1989). Intertext, v.24, n.1, s.p., 2016.

BARATA, Rodrigo Otavio Maroja. O flaneurismo na fotografia gay de Alair Gomes e de Alvin Baltrop. In: I ENCONTRO DE ANTROPOLOGIA VISUAL DA AMÉRICA AMAZÔNICA. Anais... Belém, 4-6 nov. 2014.

CONNELL, R.W. Masculinities. Cambridge: Polity Press, 1995.

.; MESSERSCHMIDT, J.W. Hegemonic masculinity: Rethinking the Concept. Gender \& Society, v.19, n.6, p.829-859, dez. 2005.

COSTA, Flavia Nacif da; FERREIRA, Thiago. Potências inscritas no corpo: do flâneur ao cruiser. Urbana, v.8, n.1, p.28-45, 2016.

CHIARELLI, Tadeu. Arte internacional brasileira. São Paulo: Lemos-Editorial, 1999.

ELLENZWEIG, Allen. The homoerotic photograph: male images from Durieu / Delacroix to Mapplethorpe. New York: Columbia University Press, 1992.

ENWEZOR, Okwui. The postcolonial constellation: contemporary art in a state of permanent transition. Research in African Literatures, v.34, n.4, p.57-82, 2003. 
FEATHERSTONE, Mike. Cultura de consumo e pós-modernismo. São Paulo: Studio Nobel, 1995.

FOUCAULT, Michel. Outros espaços. In: Estética: literatura e pintura, música e cinema - Ditos e escritos III. Rio de Janeiro: Forense Universitária, 2001, p.411-422.

GARCIA, Wilton. Arte homoerótica no Brasil: estudos contemporâneos. Revista Gênero, v.12, n.2, p.131-163, 2012.

GREEN, James N. Além do Carnaval: homossexualidade masculina no Brasil do século XX. São Paulo: Ed. Unesp, 2000

HALBERSTAM, Jack. In a queer time and place: Transgender bodies, subcultural lives. Nova York: NYU Press, 2005.

LIMA, Ivaldo Gonçalves de. O gênero da fotografia: da intersubjetividade à intercorporalidade na obra de Alair Gomes. REB, v.4, n.8, p.131-144, 2017.

MCCLINTOCK, Anne. Imperial Leather: Race, Gender and Sexuality in the Colonial Contest. Nova York, Londres: Routledge: 1995.

MENDONÇA, Carlos Camargos. E o verbo se fez homem: corpo e mídia. São Paulo: Intermeios, 2012.

MERCER, Kobena. Eros \& Diaspora. In: OGUIBE, Olu; ENWEZOR, Okwui. Reading the contemporary: African art from theory to the marketplace. Londres: Institute of International Visual Arts, 1999, p. 283-293.

MISKOLCI, Richard. O armário ampliado: notas sobre sociabilidade homoerótica na era da internet. Gênero, v. 9, n. 2, p.171-190, 2009.

Machos e Brothers: uma etnografia sobre o armário em relações homoeróticas masculinas criadas on-line. Estudos Feministas, v.21, n.1, p.301-324, 2013.

MOFFITT, Evan. Rotimi Fani-Kayode’s Ecstatic Antibodies. Transition, n. 118, p. 7486,2015 .

PEREIRA, Bruno. Heterotopias do (in)desejável: conjugando espaços e sexualidades a partir da fotografia de Alair Gomes. Periódicus, v.1, n.8, p.62-78, 2018.

PERLONGHER, Néstor O. O negócio do michê: a prostituição viril. São Paulo: Brasiliense, 1987. 
PRECIADO, Beatriz [Paul]. Cartografías queer: el flânneur perverso, la lesbiana topofóbica y la puta multicartográfica, o cómo hacer una cartografía 'zorra' con Annie Sprinkle. In: CORTÉS, J.M.G. (Org).. Cartografías Disidentes. Madrid: SEACEX, 2008.

SANTOS, Alexandre. A indisciplina do desejo: corpo masculino e fotografia. In: XXII COLÓQUIO BRASILEIRO DE HISTÓRIA DA ARTE. Anais..., 2002.

Duane Michals e Alair Gomes: documentos de si e escritas pessoais na arte contemporânea. ArtCultura, v. 10, n. 16, p. 51-65, jan.-jun. 2008.

À sombra dos rapazes em flor. Revista de História da Biblioteca Nacional, v. 4, n. 40, p. 26-31, 2009.

SONTAG, Susan. Sobre fotografia. São Paulo: Companhia das Letras, 2004.

SOUZA, Gabriel de. Alair Gomes e Robert Mapplethorpe, 2017. Disponível em: $<$ http://fdag.com.br/app/uploads/2017/o6/press-release-gomes-mapplethorpe-pt-2. pdf $>$. Acesso em: 20 maio 2018.

TAMAGNE, Florence. Mutações homossexuais. In: CORBIN, Alain; COURTINE, JeanJacques; VIGARELLO, Georges. (Ed.) História da Virilidade: A virilidade em crise? Séculos XX-XXI. Petrópolis: Vozes, 2013, p. 424-453.

VILLAAMIL, Fernando. La transformación de la identidad gay en España. Madrid: Catarata, 2004.

WILLIAMS, Carla. African-American and African Diaspora Art. GLBTQ, 2002. Disponível em: <http://www.glbtq.com>. Acesso em: 24 maio 2018.

ZAYA, Octavio. On Three Counts I Am an Outsider: The Work of Rotimi Fani-Kayode. Nka: Journal of Contemporary African Art, n. 4, p. 24-72, 1996. 